\title{
Clinical assessment of exercise capacity in patients with chronic obstructive pulmonary disease
}

\section{Avaliação clínica da capacidade do exercício em pacientes com doença pulmonar obstrutiva crônica}

Vilaró J', Resqueti VR², Fregonezi GAF²

\begin{abstract}
Background: Chronic obstructive pulmonary disease (COPD) is characterized as a multisystemic disease that reduces patient's tolerance to exercise. Nowadays, a great variety of validated tests are available for use in Respiratory Physical Therapy that are simple, practical and inexpensive. Objective: To describe the tests most used in patients with COPD to evaluate their exercise capacity and physical activity, along with some tests that potentially could be adopted for clinical evaluations in such patients. Conclusions: To be able to justify the professional quality of the respiratory physical therapists' work, tests that have been used and validated internationally must be incorporated. Moreover, it is important to choose the most appropriate tests for measuring exercise capacity and, above all, to perform a careful follow-up of the patient.
\end{abstract}

Key words: COPD; exercise capacity; walk test; muscle strength; activities of daily living

\section{Resumo}

Contextualização: A doença pulmonar obstrutiva crônica (DPOC) se caracteriza por ser uma afecção multissistêmica que leva a uma diminuição na tolerância ao exercício do paciente pneumopata. Atualmente, a Fisioterapia Respiratória dispõe de uma grande variedade de testes validados que tem como característica a sua simplicidade, praticidade e baixo custo. Objetivo: Descrever os testes de campo mais utilizados em pacientes com DPOC para avaliar a capacidade de exercício e a atividade física, assim como alguns testes que potencialmente poderiam ser adotados na avaliação clínica destes pacientes. Conclusões: Para poder justificar a qualidade do trabalho do profissional de Fisioterapia Respiratória, deve-se incorporar os testes utilizados e validados internacionalmente. Além disso, é importante escolher o teste mais adequado para medir a capacidade do exercício e, sobretudo, realizar um seguimento cuidadoso da evolução do paciente.

Palavras-chave: DPOC; capacidade de exercício; teste de caminhada; força muscular; atividades da vida diária.

Received: 05/11/07 - Revised: 24/12/07 - Accepted: 06/05/08

${ }^{1}$ Biomedicine, Universitat Pompeu Fabra; EUIFN Blanquerna, Universitat Ramon Llull; Clinical Foundation, IDIBAPS - Barcelona, Spain. ${ }^{2}$ Department of Physical Therapy, Onofre Lopes University Hospital, Universidade Federal do Rio Grande do Norte (UFRN) - Natal (RN), Brazil Correspondence to: Jordi Vilaró, EUIFN Blanquerna, Universitat Ramon Llull, Padilla 326-332, Barcelona 08027, Spain, e-mail: jordivc@blanquerna.url.edu 


\section{Introduction $: \because$.}

There has recently been a change in the paradigm for the model for evaluating patients with chronic obstructive pulmonary disease (COPD). Not long ago, the diagnosis for this disease was based mainly on abnormalities of the patient's pulmonary functions. The forced expiratory volume in the first second $\left(\mathrm{FEV}_{1}\right)$ is still substantially taken as a parameter for establishing the severity and prognosis of the disease ${ }^{1}$. However, there are other important factors which influence the impact and evolution of COPD. Factors like hypoxemia or hypercapnia, limiting functional dyspnea, low body mass composition and diminished capacity for exercise are all associated with a high risk of mortality. Recent studies have demonstrated that the numerical values of $\mathrm{FEV}_{1}$ in COPD patients have limited use when it is desired to predict the capacity for exercise, healthrelated quality of life and symptomatology ${ }^{2-4}$.

It would therefore be logical to envisage a clinical evaluation model that would, among other characteristics, bring together those relating to the degrees of dyspnea, gas exchange ratios, body composition and exercise tolerance, among COPD patients $^{5}$. Consequently, it could be affirmed that the degree of tolerance to exercise is an essential dimension in evaluating COPD patients. However, the basic problem of how to measure this continues to exist. Today, tests to evaluate exercise capacity performed in cardiopulmonary evaluation laboratories are not within the reach of the vast majority of healthcare professionals. Moreover, such tests are generally not the determining factors for the final diagnosis and for choosing the best treatment for most COPD patients. One accessible alternative for all healthcare professionals and, by extension, for all patients would therefore be simple exercise tests. In fact, as proposed by Celli et al. ${ }^{5}$ with the BODE index (B=body; $\mathrm{O}=$ obstruction; $\mathrm{D}=$ dyspnea; $\mathrm{E}=$ exercise), the 6-minute walk test (6MWT) has already become a habitually performed test for evaluating the clinical evolution of COPD patients ${ }^{5}$. This is partially due to the standardization of the test, but it is above all due to its simplicity, accessibility and great validity. However, some fundamental characteristics still remain to be defined in relation to the 6MWT. For example, these include the patient's presumed physiological load, relationships with other exercise tests, the patient's self-imposed gait speed and the capacity to maintain this over the course of time. Another important matter would be to determine whether the definition of clinical improvements from any type of intervention (respiratory rehabilitation, or lung transplantation), which is taken to be a mean of 54 meters, is really appropriate for all COPD patients, from the most to the least severe cases. For example, it is known today that if the speed spontaneously adopted by patients during the test were to be sustained over a period of time, it could be compared with their critical load or speed ${ }^{6}$. Finally, new types of tests should be explored, in order to observe the relationships between the kinetics of oxygen consumption $\left(\mathrm{VO}_{2}\right)$ and cardiopulmonary laboratory and endurance tests. In this review, the field tests that are most used for COPD patients will be covered, along with some other types of tests that potentially could be adopted for clinically evaluating such patients.

\section{Clinical tests for evaluating exercise capacity}

The clinical tests for evaluating exercise capacity are simple tests that generally consist of walking on a level surface or, alternatively, going up steps. Thus, they impose a constant or incremental load as a function of the type and time chosen. The most common tests are: the 6MWT, the incremental or shuttle walking test (SWT) and its variants, and the step test (ST). Among the variants of the walking test are the 12 minute test, first proposed by Cooper ${ }^{7}$, the two and six-minute tests described by McGavin, Gupta and McHardy ${ }^{8}$ and Butland et al. ${ }^{9}$, and the three-minute test studied recently by Iriberri et al. ${ }^{10}$.

It is important to emphasize that physical therapists are professionals capable of carrying out all the above tests. Furthermore, as the result of these tests, simple improvements in exercise tolerance test performance, submaximal or maximum aerobic capacity levels and the functional state between respiratory patients can be observed. These tests are widely used as a complementary element for clinically diagnosing exercise capacity, for pre- and post-operative assessments, for monitoring the response and progress in pulmonary and cardiac rehabilitation programs in relation to surgical processes such as transplantation and/or pulmonary resection, among other therapeutic interventions. Finally, clinical tests for the evaluation of exercise capacity may help demonstrate to patients how they are progressing in relation to their exercise capacity. They also allow morbidity/mortality data to be obtained now they also have an important role to play, given that various studies have deemed them to be an essential part of the clinical evaluation for respiratory patients.

\section{Six-minute walk test (6MWT)}

The first attempts to evaluate functional capacity through submaximal tests over a controlled period of time were made by Balke ${ }^{11}$, who devised a simple time-limited test to assess physical fitness. Subsequently, in 1968, Cooper ${ }^{7}$ developed a protocol for 12 minutes of walking to evaluate the functional capacity of a group of soldiers and McGavin, Gupta and McHardy ${ }^{8}$ introduced a 12 minute test for patients with ventilatory limitations. However, it was not until 1976 that Butland et al. ${ }^{9}$ conceptualized a walking test of 12 minutes in duration 
with other shorter variants (two and six minutes). This study indicated that the variability of the results increased with increasing duration of the walk, and that the discriminatory power of the test diminished as the length of the test decreased. These authors therefore proposed that a six-minute test would be in the middle between the reproducibility and discriminatory power of the test. Thus, from the time of this study, the six-minute walk test (6MWT) became very generally used. This test was then chosen as a clinical tool for assessing the capacity for submaximal exercise among cases of various respiratory diseases such as COPD, cystic fibrosis and asthma, and for preand post-operative assessments in cases of lung resections or transplantations ${ }^{12}$, among others. The great dissemination and use of the 6MWT are based mainly on its qualities like simplicity and practicality, since it is a test that is easy to perform, is low-cost and highly reproducible in clinical practice.

The procedure for performing a 6MWT consists of walking across a level surface between two cones or two marks on the floor that have a separation of at least 30 meters (Figure 1), at a speed chosen by the patients themselves ${ }^{13}$.

The test can be considered to demonstrate a constant load, since the load imposed, of the subject's body mass, and the gait speed do not vary over the course of the test. Because the load is constant, it is easily tolerated by patients, independent of the severity of the underlying disease. During the walking test, which is considered to be submaximal, the oxygen transportation components adequately cover the requirements imposed by the intensity of the cell metabolism and therefore the gas exchange needs for oxygen and carbon dioxide between the mitochondria, the intrinsic muscle level and the atmosphere.

On the other hand, the mitochondrial oxidative capacity does not reach its maximum limits. Under these conditions, symptoms like dyspnea and muscle fatigue are tolerable and the exercise remains below the lactic threshold and can be adequately sustained for a relatively short time. Thus, submaximal tests are the most appropriate type for evaluating physical capacity in a way that is safe and comfortable for such patients ${ }^{14}$. Perhaps for these reasons it is one of the tests most used in clinical practice. In a recent review of the literature, Solway et al. ${ }^{12}$ concluded that the 6MWT is easy to perform and is well tolerated by patients, and that it is the test that best reproduces the activities of daily living. Hence, this is a simple test that evaluates walking that is performed every day and is also standardized and requires few technical elements for its application.

However, new studies have now been published regarding temporal variations in the test ${ }^{10,15}$. These new studies were based on the justification that the first study published (Butland et al. ${ }^{9}$ ), in which variations in the duration of the walking test (two, six and 12 minutes) were compared, was conducted with a very small sample of individuals. Thus, its conclusions were extrapolated without confirmation from new comparative studies. To the current knowledge, no such comparisons have been published. Today, particularly for COPD patients, there are two variations of the test, of shorter duration (two and three minutes). These variants demonstrate high interclass correlation coefficients with the six-minute test ( $r=0.99$ and $r=0.98$, respectively) and are highly capable of evaluating and identifying limitations to exercise tolerance among such patients. In a recent study ${ }^{16}$, the three-minute test was shown to be valid and efficient for evaluating patients with severe COPD (with $\mathrm{FEV}_{1}$ less than or equal to $30 \%$ of the expected value) who, because of their large physical incapacities, severe dyspnea, severely impaired respiration and peripheral muscles, were incapable of performing the 6MWT.

Recent studies have demonstrated that the 6MWT has acceptable correlations with peak $\mathrm{VO}_{2}$ and with health-related quality of life. Furthermore, it has been shown to be a good predictor of mortality among COPD patients and among those undergoing lung volume reduction surgery ${ }^{17-19}$. Since this is a simple test for detecting changes produced by therapeutic interventions such as rehabilitation ${ }^{20}$, the 6MWT is used in approximately $80 \%$ of pulmonary rehabilitation programs ${ }^{21}$. Today, formulae capable of predicting individuals' walking capacities exist in relation to variables such as gender and age $\mathrm{ag}^{22-24}$. It has also now been determined that the minimum clinically significant differences that patients are capable of perceiving as an improvement between one test and another is 54 meters ${ }^{25}$. Today, the walking test provides standardization that ensures that measurements attain the quality levels established by the American Thoracic Society (ATS).

Moreover, in a recent cohort study on 294 patients with COPD who were followed up by means of an annual 6MWT for five years, it was demonstrated that over the course of time, the distance walked declined and that this decline was more notable and more significant among the patients with severely obstructed air flow ( $\mathrm{FEV}_{1}<50 \%$ of expected values). It was also observed that the distance walked decreased linearly with increasing severity of the disease ${ }^{26}$.

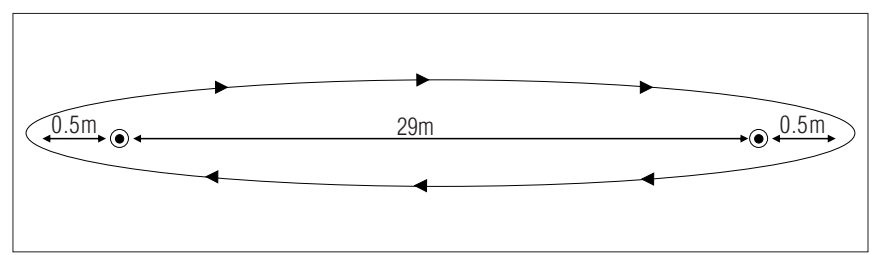

Figure 1. Distance to be walked during the six-minute walk test (6MWT). The cones, or the marking son the floor, indicate the points at which the changes in direction should be made. They are positioned at a distance of $0.5 \mathrm{~m}$ from the extremities of the perimeter, to allow the patient to turn. 


\section{Walking test with progressive loading}

\section{Shuttle walk test (ISWT - incremental shuttle walking test and ESWT - endurance shuttle walking test}

The walking test with progressive loads or shuttle walking test (SWT) was introduced by Singh et al. ${ }^{27}$. The SWT is a modification for patients with ventilatory limitations derived from the 20-meter shuttle test that was initially described for evaluating physical capacity among children, active adults and general athletes ${ }^{28,29}$. It consists of repeatedly walking to and fro across a known distance of 10 meters on a level surface, around a course marked out by two cones separated by a distance of nine meters (Figure 2). A single audible beep indicates the time within which the patient should cover the predetermined distance, reach the cone and change direction to return to the other cone. A triple beep indicates the need to go faster to cover the distance between the cones. Every minute, the time between the beeps is reduced such that the patient needs to increase his walking speed in order to reach the cone at the time indicated. The test finishes when the patient is incapable of reaching the cone on two consecutive occasions or when the patient wishes to stop the test because of symptoms triggered by increasing the walking speed. Thus, this is an incremental test with stages of up to 12 speed levels that produces physiological loads resembling an incremental test using a cycle ergometer ${ }^{30}$. It is a standardized test with good reproducibility and it is efficient for evaluating the physical capacity of patients with respiratory disease, to prescribe treatment. Furthermore, it is a useful evaluation parameter for determining interventions to be implemented for COPD patients. The SWT has demonstrated a good correlation with maximum $\mathrm{VO}_{2}$ obtained during conventional incremental effort tests.

A modified version of the SWT (called SWTp), for COPD patients at various GOLD stages, has now been published. The aim is to improve the logistics of the test in regard to what is considered to be its weakest point: the external audible sig$\mathrm{nal}^{31}$. In this study, the need to improve the external audible signal is justified in terms of the aim of improving the yield of patients who are in a more severely impaired functional physical condition. Such patients demonstrate a certain difficulty

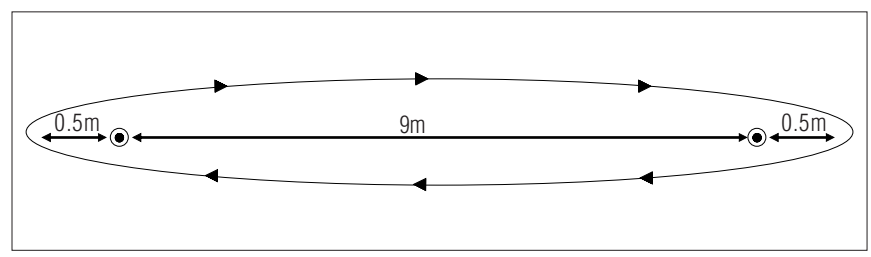

Figure 2. Distance to be walked during the shuttle walk test (SWT). The cones, or the markings on the floor, indicate the points at which the changes in direction should be made. They are positioned at a distance of $0.5 \mathrm{~m}$ from the extremities of the perimeter, to allow the patient to turn. in adjusting their walking pace in response to the stimulus, to increase their speed in accordance with each beep. A step-bystep audible stimulation was introduced to the test, and this showed a very significant interclass correlation $(\mathrm{r}=0.95)$ in relation to the distance walked, with a confidence interval of 0.85 to $0.95(\mathrm{p}<0.0001)$. According to this study, there were some advantages in using the SWTp, since the patients were capable of walking further (an extra 28 to 32 meters). The learning effect in using the SWTp was also smaller than in using the SWT, since the patients adapted better to this test with a continuous audible signal. Moreover, on the SWTp, the patients walked greater distances than they did in the SWT, possibly due to greater mechanical efficiency associated with slightly greater oxygen consumption, in relation to the conventional SWT ${ }^{31}$.

Another recent development regarding the logistics of the SWT was its change in name to the incremental shuttle walking test (ISWT), with the development of a new test called the endurance shuttle walking test (ESWT) ${ }^{32}$. The aim of the ESWT was to evaluate the maximum capacity through a field test at submaximal intensity that was reproducible and not very lengthy (in time) for patients and for the evaluator. Thus, a non-incremental test was developed, with constant speed and loads that were based on using a percentage of constant load related to the maximum previously obtained from an SWT or ISWT. The percentage usually applied was the intensity attained at $85 \%$ of the peak oxygen consumption $\left(\mathrm{VO}_{2}\right)$. The results demonstrated that the test demonstrated good reproducibility after just one practice test, and good sensitivity for evaluating the changes following respiratory rehabilitation programs.

\section{Step test}

Even though the step test is little used or standardized for patients with respiratory diseases, it demonstrates a good heart rate response in relation to the maximum oxygen consumption. Thus, the heart rate level obtained during the test, and particularly the maximum rate achieved, can be used to classify patients at different degrees of physical capacity. There are several variations in this type of test. Smith and Gilligan ${ }^{33}$ developed a seated step test that was shown to be very useful for evaluating exercise tolerance, physical fitness and endurance among elderly people with limited physical capacities and in a debilitated state. Although this test is classified as submaximal, it is less intense than submaximal or maximum tests on a treadmill or ergometric bicycle. The test consists of going up and down four levels of steps of different height: $15.2 \mathrm{~cm}$ (stage 1), $30.5 \mathrm{~cm}$ (stage 2), $45.7 \mathrm{~cm}$ (stage 3 ) and, in stage 4, the same height as in stage 3 is maintained with the addition of alternated arm movements. Each stage of the test represents energy expenditure of approximately 8.05, 10.15, 12.25 and 13.65mL/ 
$\mathrm{kg} / \mathrm{min}$, respectively. To reach the next stage of the test, a heart rate lower than $75 \%$ of the reference maximum (expected) must be attained in the fifth minute of the test. Arterial pressure needs to be monitored before starting the test and after two and five minutes.

Other tests using steps have been developed, such as the Tecumseh step test by Montoye ${ }^{34}$, the YCMCA step test by Kasch et al. ${ }^{35}$ and the Chester step test ${ }^{36}$. These have different applications and methodologies but, so far, none of them have been standardized and referenced in the literature for evaluations with patients with respiratory diseases.

Some respiratory rehabilitation programs include the physical activity of going up steps as a complementary training method. For patients with chronic airflow limitations, going up steps is an exhausting exercise and it leads to a physiological response in terms of $\mathrm{VO}_{2}, \mathrm{~V}_{\mathrm{E}}$, heart rate and related symptoms that are similar to the responses in maximum tests ${ }^{37,38}$. Although the step test is simple, cheap and easy to apply, few studies have chosen step tests to evaluate physical capacity among individuals with airflow limitations.

\section{Arm exercise test without load}

The validity and reliability of an arm exercise test without load has recently been evaluated ${ }^{39}$. Although this test was developed approximately 20 years ago by Celli, Rassulo and Make ${ }^{40}$, it is still little used for evaluating COPD patients ${ }^{41,42}$. The test consists of moving hoops or rings between four fixed pins at two levels on a vertical frame, while seated on a chair with back support (Figure 3). Two pins are positioned at shoulder height and the other two at $20 \mathrm{~cm}$ above shoulder level. Ten hoops or rings are placed on each of the lower pins, and each hoop should weigh approximately $14.17 \mathrm{~g}(1 / 2 \mathrm{Oz})$. The patients are instructed to use both hands to move one hoop or ring at a time from the lower to the upper level. After repositioning all the hoops or rings from the lower level to the upper level, the patients then put the hoops back on the lower level, and so on.

The total score from the test is the number of hoops moved over a six-minute period. It is possible to stop to rest because of fatigue, dyspnea or other discomfort, and to start doing the test again as soon as feeling more comfortable, while keeping on measuring the time on the chronometer. This recent study demonstrated high test-retest correlation coefficient ( $\mathrm{r}=0.91$, $\mathrm{p}<0.001$ ), with the pulmonary function parameters $\mathrm{FEV}_{1} \%$ $(\mathrm{r}=0.55, \mathrm{p}<0.003)$ and forced vital capacity (FVC\%) $(\mathrm{r}=0.60$, $\mathrm{p}<0.001$ ), and in some domains and subdomains of the Pulmonary Functional Status Dyspnea Questionnaire. Although it has been little used, the arm exercise test without load demonstrates great clinical and scientific potential, since the feeling of dyspnea due to activities using the upper limbs is considered to be one of the biggest problems among patients with moderate or severe COPD. However, many respiratory rehabilitation programs do not give any emphasis to evaluating and training the upper limbs.

\section{Tests for measuring muscle function}

Muscle function tests have the aim of evaluating the muscular strength or resistance capacity that an individual is capable of developing. They have been used for evaluating respiratory illnesses since the mid-1980s ${ }^{43}$. The purpose of these measurements is to determine the degree of decline in strength or resistance produced by the impact of the disease and also to evaluate the improvements felt after a pulmonary rehabilitation program. In cases of COPD, the strength of the respiratory musculature and also of the skeletal or peripheral musculature is measured ${ }^{44}$. To measure the strength of the peripheral musculature, the following different methods can be used: cable dynamometers, electronic dynamometers, test of one maximum repetition (1MR), and respiratory muscle strength evaluation.

\section{Cable dynamometry: isometric strength}

Cable dynamometers are only used to measure isometric strength, since they are unable to allow joint movement ${ }^{45}$. This system may be efficient for individuals with osteoarticular abnormalities or movement difficulties, or for bedridden patients. However, a structure that is stable and sufficiently rigid for the dynamometer to be attached to it needs to be made available. Manual or handgrip dynamometers are one of the types most used, because of their ease of use and lack of need for attachments. However, they have the drawback of only allowing strength measurements on the flexor muscles of the

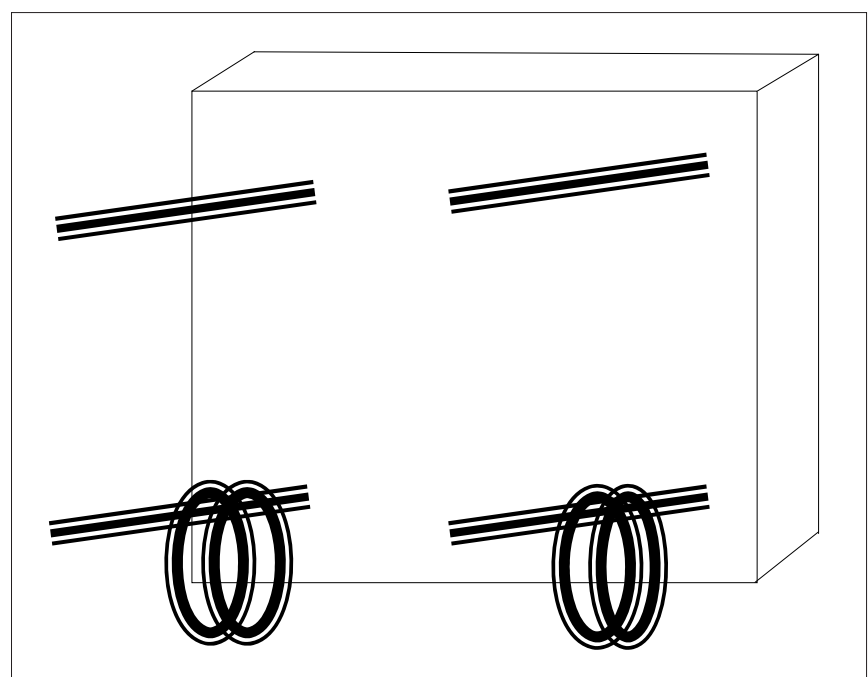

Figure 3. Example of the structure of the equipment used in the arm exercise test without load. 
fingers. Although reference equations are available, it is known that for COPD patients, muscle strength is better preserved in the musculature of the upper limbs than of the lower limbs ${ }^{46}$.

\section{Motorized dynamometry: isokinetic strength}

Motorized dynamometers are systems used to measure isokinetic strength and are essentially used to evaluate the performance of voluntary contractile muscles. Mechanical, physiological and psychological characteristics are involved in this evaluation procedure. In cases of respiratory diseases, and especially COPD, lower-limb evaluation is most frequently used. Isokinetic evaluation of the lower limbs in COPD cases has been converted into a gold standard, particularly for scientific research, since this is a system that is more objective and reliable because of the control over movement and speed, thereby avoiding undesirable effects produced by other joints ${ }^{47}$. However, the smallness of the movements produced when subjects are poorly adapted to angular displacement and the fact that this is not a movement reproducible in nature may produce errors in the results ${ }^{48}$. It must also be noted that studies have shown that isokinetic evaluations in the lower limbs in COPD cases have low correlations with the habitual activities of daily living ${ }^{49}$.

\section{Maximum repetitions: isotonic strength}

The test of one maximum repetition (1MR) measures the maximum voluntary contraction or isotonic strength. It consists of moving a weight through a specific joint movement. Rehabilitation centers very often have apparatus available for measuring this, especially because such equipment is very simple and low-cost. This is a dynamic measurement that is closely related to the movements produced during activities of daily living ${ }^{50,51}$. Thus, the two-way traffic of information obtained is easily applicable for observing the evolution of patients with impaired peripheral muscle strength and for evaluating training in which they undergo ${ }^{52}$. However, this is a voluntary test that requires a learning process that differs from other evaluation techniques because it requires spontaneous joint movements ${ }^{52,53}$.

\section{Evaluation of respiratory muscle strength}

Measurement of respiratory muscle strength is considered today to have great value in evaluating patients with respiratory impairments, especially among patients with neuromuscular diseases. In the cases of COPD, the strength of the inspiratory muscles is usually diminished due to mechanical changes caused by low levels of direct insufflation derived from air trapping, and not because of changes in muscle contractile properties ${ }^{54,55}$. Conventional strength measurements are generated from maximum isometric contractions of the residual volume (RV) for the inspiratory muscles, and from the total pulmonary capacity (TPC) for the expiratory muscles. The results are values for the maximum inspiratory pressure (MIP) and/or the maximum expiratory pressure (MEP). These measurements serve for the evaluation of maximum strength. Currently, only one device for evaluating respiratory muscle endurance is available commercially, even though this is the property that is most susceptible to changes following specific training programs ${ }^{56}$. It is now known that identifying the strength of the respiratory muscles, and particularly the strength of the inspiratory muscles, is of fundamental importance in determining whether inspiratory muscle training (IMT) should be included in rehabilitation programs. Generally, when MIP is $<60 \mathrm{~cm} \mathrm{H}_{2} 0$, training based on the values obtained is advised ${ }^{57}$. Although there is a great contradiction in the role of IMT in respiratory muscle rehabilitation programs for COPD patients, there are studies that demonstrate the efficacy of training using linear valves to improve the inspiratory muscle strength and resistance ${ }^{58}$. IMT with a linear load and threshold-type valve, at MIP values of $30 \%$ has been shown to be efficient in increasing the speed of muscle contraction ${ }^{59}$ thus leading to a more favorable respiratory pattern, with shorter inspiratory time, increased expiratory time and increased muscle relaxation time during the respiratory cycle. Despite the advances in relation to IMT, some points still need to be clarified in relation to IMT in COPD cases: the type of training that would be most efficient, i.e., strength, endurance or mixed training; the techniques that should be used for evaluating the IMT effects, i.e., muscle strength and/or resistance measurements; the magnitude of the improvements that really should be expected following IMT, given that the diaphragm in COPD patients seems to be more active and more susceptible to fatigue than that of healthy subjects ${ }^{60}$; and lastly, whether IMT can be considered to be a valid alternative for improving the functional capacity of COPD patients. Consequently, these responses are important for defining and standardizing a training and evaluation model for use as a component of respiratory rehabilitation programs for COPD patients.

\section{Measurement systems for activities of daily living}

The instruments that are now available for evaluating the quantity and intensity of activities of daily living (ADLs) among patients with COPD are: ADL questionnaires and movement analysis systems, id est. spatial accelerometers and pedometers. Multidimensional evaluation of COPD makes it possible to question the repercussions of intolerance to exercise on the habitual physical activities of such patients. These questionnaires, 
spatial accelerometers and pedometers are instruments that are not regularly implemented in clinical evaluations, mainly because ADLs have not been habitually studied and they have also not been a topic of interest in scientific investigations until now. However, this is now an ideal moment to seek new tools that will enable simple but objective determinations of the ADL levels achieved by COPD patients and the impact of this disease on their level of sedentarism in relation to the healthy population. With this thinking in mind, the Dynaport ${ }^{\circledR}$ (Activity Monitor, McRoberts BV, The Hague, Netherlands) accelerometer was developed as an activity monitor and has been shown to be more efficient and complete for evaluating ADLs, in comparison with other equipment.

\section{Questionnaires on physical activities in daily living}

ADL questionnaires started to be used among healthy populations at the beginning of the 1980s, to evaluate the levels of physical activity and sedentarism among sport participants ${ }^{61}$. These questionnaires were then adapted and incorporated into evaluations of elderly people ${ }^{62}$ because of their low cost, the short time taken to apply them and the ease of using them in epidemiological studies ${ }^{63}$. Several questionnaires have not been adapted or specifically designed for evaluating ADLs among COPD patients ${ }^{64,65}$. In these, the levels of physical activity achieved and its relationship with the perceived dyspnea are determined. These questionnaires have been shown to be valid instruments for evaluating ADLs, which have a close relationship with the 6MWT and with quality of life ${ }^{66}$. They have also been shown to be good predictors of mortality, independent of pulmonary function and the body mass index, among other variables ${ }^{67}$. These questionnaires are tools that, by their nature, enable wide-ranging use within clinical contexts. Furthermore, because of their low cost, ease of application and lack of need for training on how to use them, any healthcare professional can apply these questionnaires. The possibility of having tests that are easily performed in clinical practice has provided a substantial improvement in the multidimensional evaluation of $\mathrm{COPD}^{68-70}$.

\section{Spatial accelerometers}

Accelerometers are small sensors that are coupled to the subject's body and allow movements to be recorded along three spatial axes: X (mediolateral), Y (anteroposterior) and $\mathrm{Z}$ (vertical). At the same time the displacement speed along each of the axes is measured, the duration of the movements and periods with and without stability of movement are also recorded. These systems started to be used in the field of physical activity in the mid-1990s ${ }^{71}$. The purpose of this equipment is to evaluate the type, intensity and duration of physical activities that are performed by sport participants with a precision tool ${ }^{72}$. The acceptable scientific results and good correlations with maximum $\mathrm{VO}_{2}$ that have been found in the studies conducted have demonstrated the efficacy of this equipment for measuring the physical activity levels among healthy subjects. Even though the results found have been promising, this equipment is very sensitive to the mode and intensity of the exercise performed $^{73}$. In the studies that have been undertaken, it has been observed that, in order to obtain a reliable measurement of the activity analyzed through these triaxial accelerometers during moderate or intense activities, at least three or four days of monitoring are needed ${ }^{74}$. Accelerometers used among COPD patients in relation to their ADLs and while walking have been shown to provide reliable and valid measurements ${ }^{75}$. Recently, a new activity-monitoring accelerometer $\left(\right.$ Dynaport $\left.^{\circledR}\right)$ was developed with the aim of precisely demonstrating the patients' behavior within their real environments. This apparatus is capable of differentiating between movement patterns (walking or cycling, among others) or body positions (standing, seated or lying down), and is capable of indicating the intensity of each movement. In a recent study, Pitta et al. ${ }^{76,77}$ demonstrated that the Dynaport ${ }^{\circledR}$ activity monitor was capable of measuring the ADLs of COPD patients. They found marked physical inactivity among these patients, in comparison with sedentary individuals.

\section{Pedometers}

Pedometers consist of small sensors that are positioned at certain places on the body, usually the waist, with the aim of evaluating the vertical oscillations of the body. The oscillations are counted as the total number of accumulated movements, which thus determines the total number of steps made over the evaluated period and the distance walked. This is a low-cost system that is very accessible and easy to use. Furthermore, it evaluates the physical activity that is performed ${ }^{78}$. Despite these advantages, it has the drawback of recording errors in the measurements when few body movements are made, such as while walking or if more than one device is used at the same time at different places on the body ${ }^{79}$. In studies evaluating the sensitivity of pedometers through ANOVA, it has been observed that the sensitivity of the evaluations increase when the results found are combined with the heart rate during the movements $^{80}$. Despite the drawbacks of pedometers, they posses great potential when used in association with heart rate measurements, since they enable evaluations of physical activity levels, particularly while walking, in epidemiological studies on 
large populations. In view of the activities that it is desired to evaluate, particularly if related to walking, this must be considered to be an excellent method whenever the evaluated activities need to be compared with sedentarism.

Recent studies have suggested that the technical systems for measuring physical activity and ADLs, such as accelerometers or pedometers, are useful for detecting body movements during low-intensity walking. However, their efficacy decreases if they are used to estimate the energy expenditure associated with high-speed walking. Finally, for reliable measurements to be obtained, it is recommended that evaluations using pedometers should be performed over periods of more than three days.

\section{Conclusions : : $:$}

With the new tools introduced recently for evaluating cases of COPD, it has become insufficient to use respiratory parameters such as $\mathrm{FEV}_{1}$ alone to establish the degree of physiopathological involvement and the functional prognosis for the disease, as already recognized in the medical literature. Several factors contribute towards predicting the impact and evolution of patients with COPD and assist in evaluations following interventions such as respiratory rehabilitation. The 6MWT, ISWT, ESWT, peripheral and respiratory muscle function tests, BODE index and ADL monitoring are important tools that are useful, simple, easy to apply and important for defining the severity and clinical course of the disease. Other tests have demonstrated great potential that still has not been explored, such as the step test, 2 and 3 minute walking tests and the arm test without a load. Therefore, physical therapists involved in respiratory rehabilitation have a wide variety of tests available for clinical evaluations on the exercise capacity of COPD patients. It is important that the use of sets of evaluations are always considered, in order to plan the best treatment possible and establish the best therapeutic options for following up the evolutions and treatments of the disease and the respiratory rehabilitation implemented programs.

\section{References $: \because$.}

1. Pauwels RA, Buist AS, Ma P, Jenkins CR, Hurd SS; GOLD Scientific Committee. Global strategy for the diagnosis, management, and prevention of chronic obstructive pulmonary disease: National Heart, Lung, and Blood Institute and World Health Organization Global Initiative for Chronic Obstructive Lung Disease (GOLD): Executive summary. Respir Care. 2001;46(8):798-825.

2. O'Donnell DE, Lam M, Webb KA. Measurement of symptoms, lung hyperinflation, and endurance during exercise in chronic obstructive pulmonary disease. Am J Respir Crit Care Med. 1998;158(5 Pt 1): $1557-65$

3. Jones PW, Quirk FH, Baveystock CM, Littlejohns P. A self-complete measure of health status for chronic airflow limitation. The St. George's Respiratory Questionnaire. Am Rev Respir Dis. 1992;145(6):1321-7.
4. Mahler DA, Weinberg DH, Wells CK, Feinstein AR. The measurement of dyspnea. Contents, interobserver agreement, and physiologic correlates of two new clinical indexes. Chest. 1984;85(6):751-8.

5. Celli BR, Cote CG, Marin JM, Casanova C, Montes de Oca M, Mendez RA et al. The body-mass index, airflow obstruction, dyspnea, and exercise capacity index in chronic obstructive pulmonary disease. N Engl J Med. 2004;350(10):1005-12.

6. Neder JA, Jones PW, Nery LE, Whipp BJ. Determinants of the exercise endurance capacity in patients with chronic obstructive pulmonary disease. The power-duration relationship. Am J Respir Crit Care Med. 2000; 162(2 Pt 1):497-504.

7. Cooper KH. A means of assessing maximal oxygen intake. Correlation between field and treadmill testing. JAMA. 1968;203(3):201-4. 
8. McGavin CR, Gupta SP, McHardy GJ. Twelve-minute walking test for assessing disability in chronic bronchitis. Br Med J. 1976;1(6013): 822-3.

9. Butland RJ, Pang J, Gross ER, Woodcock AA, Geddes DM. Two-, six-, and 12-minute walking tests in respiratory disease. Br Med J (Clin Res Ed). 1982:284(6329):1607-8.

10. Iriberri M, Gáldiz JB, Gorostiza A, Ansola P, Jaca C. Comparison of the distances covered during 3 and 6 min walking test. Respir Med. 2002;96(10):812-6.

11. Balke B. A simple field test for the assessment of physical fitness. Rep 63-6. Rep Civ Aeromed Res Inst US. 1963:1-8.

12. Solway S, Brooks D, Lacasse $Y$, Thomas S. A qualitative systematic overview of the measurement properties of functional walk tests used in the cardiorespiratory domain. Chest. 2001;119(1):256-70.

13. ATS Committee on Proficiency Standards for Clinical Pulmonary Function Laboratories. ATS statement: guidelines for six minute walk test. Am J Respir Crit Care Med. 2002;166(1):111-7.

14. Roca J, Rincón FB, Casan P, Ortega F, Puente-Maestu L, Togores B. Pruebas de Exercício Cardiopulmonar. Arch Bronconeumol. 2001;37:247-68.

15. Leung AS, Chan KK, Sykes K, Chan KS. Reliability, validity, and responsiveness of a 2-min walk test to assess exercise capacity of COPD patients. Chest. 2006;130(1):119-25.

16. Resqueti VR, Gorostiza A, Batís J, Lopes de Santa Maria E, Casan P, Güell R. Beneficios de un programa de rehabilitación respiratoria domiciliaria en pacientes con EPOC grave. Arch Bronconeumol. 2007;43(11):599-604

17. Gerardi DA, Lovett L, Benoit-Connors ML, Reardon JZ, ZuWallack RL. Variables related to increased mortality following out-patient pulmonary rehabilitation. Eur Respir J. 1996;9(3):431-5.

18. Guyatt GH, Townsend M, Keller J, Singer J, Nogradi S. Measuring functional status in chronic lung disease: conclusions from a randomized control trial. Respir Med. 1991;85 Suppl B:17-21.

19. Szekely LA, Oelberg DA, Wright C, Johnson DC, Wain J, Trotman-Dickenson $B$ et al. Preoperative predictors of operative morbidity and mortality in COPD patients undergoing bilateral lung volume reduction surgery Chest. 1997;111(3):550-8.

20. Lacasse Y, Brosseau L, Milne S, Martin S, Wong E, Guyatt GH et al. Pulmonary rehabilitation for chronic obstructive pulmonary disease. Cochrane Database Syst Rev. 2002;(3):CD003793.

21. Elpern EH, Stevens D, Kesten S. Variability in performance of timed walk tests in pulmonary rehabilitation programs. Chest. 2000;118(1):98-105.

22. Enright PL, Sherrill DL. Reference equations for the six-minute walk in healthy adults. Am J Respir Crit Care Med. 1998;158(5 Pt 1):1384-7.

23. Troosters T, Gosselink R, Decramer M. Six minute walking distance in healthy elderly subjects. Eur Respir J. 1999;14(2):270-4.

24. Gibbons WJ, Fruchter N, Sloan S, Levy RD. Reference values for a multiple repetition 6 -minute walk test in healthy adults older than 20 years. J Cardiopulm Rehabil. 2001;21(2):87-93.
25. Redelmeier DA, Bayoumi AM, Goldstein RS, Guyatt GH. Interpreting small differences in functional status: the Six Minute Walk test in chronic lung disease patients. Am J Respir Crit Care Med. 1997;155(4):1278-82.

26. Casanova C, Cote CG, Marin JM, de Torres JP, Aguirre-Jaime A, Mendez $R$ et al. The 6-min walking distance: long-term follow up in patients with COPD Eur Respir J. 2007;29(3):535-40.

27. Singh SJ, Morgan MD, Scott S, Walters D, Hardman AE. Development of a shuttle walking test of disability in patients with chronic airways obstruction. Thorax. 1992;47(12):1019-24.

28. Léger LA, Mercier D, Gadoury C, Lambert J. The multistage 20 metre shuttle run for aerobic fitness. J Sports Sci. 1988;6(2):93-101.

29. Léger LA, Lambert J. A maximal multistage 20-m shuttle run test to predict V0, max. Eur J Appl Physiol Occup Physiol. 1982;49(1):1-12.

30. Morales FJ, Montemayor T, Martinez A. Shuttle versus six-minute walk test in the prediction of outcome in chronic heart failure. Int $\mathrm{J}$ Cardiol. 2000;76(2-3):101-5.

31. Rosa FW, Camelier AA, Fleig Mayer A, Jardim JR. Optimización de la capacidad de realización de ejercicio físico mediante una prueba de la lanzadera por tramos con estimulación auditiva continúa en pacientes con EPOC. Arch Bronconeumol. 2006;42(7):338-43.

32. Revill SM, Morgan MD, Singh SJ, Williams J, Hardman AE. The endurance shuttle walk: a new field test for the assessment of endurance capacity in chronic osbtructive pulmonary disease. Thorax. 1999;54(3):213-22.

33. Smith EL, Gilligan C. Physical activity prescription for the older adult. Phys and Sports Med. 1983;11:91-101.

34. Montoye HJ. Physical Activity and Health: An Epidemiologic Study of ands entire Community. Englew Cliffs: Prentice-Hall; 1975.

35. Kasch FW, Phillips WH, Ross WD, Carter JE, Boyer JL. A comparison of maximal oxygen uptake by treadmill and step-test procedures. J Appl Physiol. 1966;21(4):1387-98.

36. Leenders NY, Nelson TE, Sherman WM. Ability of different physical activity monitors to detect movement during treadmill walking. Int J Sports Med. 2003;24(1):43-50.

37. Pollock M, Roa J, Benditt J, Celli B. Estimation of ventilatory reserve by stair climbing. A study in patients with chronic airflow obstruction. Chest. 1993;104(5):1378-83.

38. Probst VS, Troosters T, Pitta F, Decramer M, Gosselink R. Cardiopulmonary stress during exercise training in patients with COPD. Eur Respir J. 2006;27(6):1110-8.

39. Zhan S, Cerny FJ, Gibbons WJ, Mador MJ, Wu YW. Development of an unsupported arm exercise test in patients with chronic obstructive pulmonary disease. J Cardiopulm Rehabil. 2006;26(3):180-7.

40. Celli BR, Rassulo J, Make BJ. Dyssynchronous breathing during arm but not leg exercise in patients with chronic airflow obstruction. N Engl J Med. 1986;314(23):1485-90.

41. Bauldoff GS, Hoffman LA, Sciurba F, Zullo TG. Home-based, upper-arm exercise training for patients with chronic obstructive pulmonary disease. Heart Lung. 1996;25(4):288-94. 
42. Criner GJ, Celli BR. Effect of unsupported arm exercise on ventilatory muscle recruitment in patients with severe chronic airflow obstruction. Am Rev Respir Dis. 1988;138(4):856-61.

43. Serres I, Varray A, Vallet G, Micallef JP, Préfaut C. Improved skeletal muscle performance after individualized exercise training in patients with chronic obstructive pulmonary disease. J Cardiopulm Rehabil. 1997;17(4):232-8.

44. American Thoracic Society/European Respiratory Society. ATS/ERS Statement on respiratory muscle testing. Am J Respir Crit Care Med. 2002;166(4):518-624.

45. Thorland WG, Tipton CM, Lohman TG, Bowers RW, Housh TJ, Johnson GO et al. Midwest wrestling study: prediction of minimal weight for high school wrestlers. Med Sci Sports Exerc. 1991;23(9):1102-10.

46. Frontera WR, Hughes VA, Lutz KJ, Evans WJ. A cross-sectional study of muscle strength and mass in 45- to 78-yr-old men and women. J Appl Physiol. 1991;71(2):644-50.

47. Abernethy P, Wilson G, Logan P. Strength and power assessment. Issues, controversies and challenges. Sports Med. 1995;19(6):401-17.

48. Winter DA, Wells RP, Orr GW. Errors in the use of isokinetic dynamometers. Eur J Appl Physiol Occup Physiol. 1981;46(4):397-408.

49. Greenberger HB, Paterno MV. Relationship of knee extensor strength and hopping test performance in the assessment of lower extremity function. $J$ Orthop Sports Phys Ther. 1995;22(5):202-6.

50. Kraemer WJ, Adams K, Cafarelli E, Dudley GA, Dooly C, Feigenbaum MS et al. American College of Sports Medicine position stand. Progression models in resistance training for healthy adults. Med Sci Sports Exerc. 2002;34(2):364-80.

51. Casas A, Vilaro J, Rabinovich R, Mayer A, Barberà JA, Rodriguez-Roisin $R$ et al. Encouraged 6-min walking test indicates maximum sustainable exercise in COPD patients. Chest. 2005;128(1):55-61.

52. Abernethy P, Wilson G, Logan P. Strength and power assessment. Issues, controversies and challenges. Sports Med. 1995;19(6):401-17.

53. Abernethy PJ, Jürimäe J. Cross-sectional and Iongitudinal uses of isoinertial, isometric, and isokinetic dynamometry. Med Sci Sports Exerc. 1996;28(9):1180-7.

54. Orozco-Levi M, Gea J, Lloreta JL, Félez M, Minguella J, Serrano S et al. Subcellular adaptation of the human diaphragm in chronic obstructive pulmonary disease. Eur Respir J. 1999;13(2):371-8.

55. Levine S, Nguyen T, Kaiser LR, Rubinstein NA, Maislin G, Gregory $C$ et al. Human diaphragm remodeling associated with chronic obstructive pulmonary disease: clinical implications. Am J Respir Crit Care Med. 2003;168(6):706-13.

56. Ramirez-Sarmiento A, Orozco-Levi M, Guell R, Barreiro E, Hernandez N, Mota S et al. Inspiratory muscle training in patients with chronic obstructive pulmonary disease: structural adaptation and physiologic outcomes. Am J Respir Crit Care Med. 2002;166(11):1491-7.

57. Lötters F, van Tol B, Kwakkel G, Gosselink R. Effects of controlled inspiratory muscle training in patients with COPD: a meta-analysis. Eur Resp J. 2002;20(3):570-6.
58. Weiner $P$, Azgad $Y$, Ganam R. Inspiratory muscle training combined with general exercise reconditioning in patients with COPD. Chest. 1992;102(5):1351-6.

59. Villafranca C, Borzone G, Leiva A, Lisboa C. Effects of inspiratory muscle training with an intermediate load on inspiratory power output in COPD. Eur Respir J. 1998;11(1):28-33.

60. Sinderby C, Beck J, Spahija J, Weinberg J, Grassino A. Voluntary activation of the human diaphragm in health and disease. J Appl Physiol. 1998;85(6):2146-58.

61. Baecke JA, Burema J, Frijters JE. A short questionnaire for the measurement of habitual physical activity in epidemiological studies. Am J Clin Nut. 1982;36(5):936-42.

62. Voorrips LE, Ravelli AC, Dongelmans PC, Deurenberg P, Van Staveren WA. A physical activity questionnaire for the elderly. Med Sci Sports Exerc. 1991;23(8):974-9.

63. Washburn RA, Montoye HJ. The assessment of physical activity by questionnaire. Am J Epidemiol. 1986;123(4):563-76.

64. Garrod R, Bestall JC, Paul EA, Wedzicha JA, Jones PW. Development and validation of a standardized measure of activity of daily living in patients with severe COPD: the London Chest Activity of Daily Living scale (LCADL). Respir Med. 2000;94(6):589-96.

65. Yohannes AM, Greenwood YA, Connolly MJ. Reliability of the Manchester Respiratory Activities of Daily Living Questionnaire as a postal questionnaire. Age Ageing. 2002;31(5):355-8.

66. Garrod R, Paul EA, Wedzicha JA. An evaluation of the reliability and sensitivity of the London Chest Activity of Daily Living Scale (LCADL). Respir Med. 2002;96(9):725-30.

67. Yohannes AM, Baldwin RC, Connolly M. Mortality predictors in disabling chronic obstructive pulmonary disease in old age. Age Ageing. 2002;31(2):137-40.

68. Saey D, Debigare R, LeBlanc P, Mador MJ, Cote CH, Jobin J et al. Contractile leg fatigue after cycle exercise: a factor limiting exercise in patients with chronic obstructive pulmonary disease. Am J Respir Crit Care Med. 2003;168(4):425-30.

69. Couillard A, Maltais F, Saey D, Debigaré R, Michaud A, Koechlin C et al. Exercise-induced quadriceps oxidative stress and peripheral muscle dysfunction in patients with chronic obstructive pulmonary disease. Am J Respir Crit Care Med. 2003;167(12):1664-9.

70. Serres I, Gautier V, Varray A, Préfaut C. Impaired skeletal muscle endurance related to physical inactivity and altered lung function in COPD patients. Chest. 1998;113(4):900-5.

71. Matthews CE, Freedson PS. Field trial of athree-dimensional activity monitor: comparison with self report. Sci Sports Exerc. 1995;27(7):1071-8.

72. Eston RG, Rowlands AV, Ingledew DK. Validity of heart rate, pedometry, and accelerometry for predicting the energy cost of children's activities. J Appl Physiol. 1998;84(1):362-71.

73. Fehling PC, Smith DL, Warner SE, Dalsky GP. Comparison of accelerometers with oxygen consumption in older adults during exercise. Med Sci Sports Exerc. 1999;31(1):171-5. 
74. Matthews CE, Ainsworth BE, Thompson RW, Bassett DR Jr. Sources of variance in daily physical activity levels as measured by an accelerometer. Med Sci Sports Exerc. 2002;34(8):1376-81.

75. Steele BG, Holt L, Belza B, Ferris S, Lakshminaryan S, Buchner DM. Quantitating physical activity in COPD using a triaxial accelerometer Chest. 2000;117(5):1359-67.

76. Pitta F, Troosters T, Spruit MA, Probst VS, Decramer M, Gosselink R. Characteristics of physical activities in daily life in chronic obstructive pulmonary disease. Am J Respir Crit Care Med. 2005;171(9):972-7.
77. Pitta F, Troosters T, Spruit MA, Decramer M, Gosselink R. Activity monitoring for assessment of physical activities in daily life in patients with chronic obstructive pulmonary disease. Arch Phys Med Rehabil.2005;86(10):1979-85.

78. Leenders NYJM, Sherman WM, Nagaraja HN. Comparisons of four methods of estimating physical activity in adult women. Med Sci Sports Exerc. 2000;32(7):1320-6.

79. Buckley JP, Sim J, Eston RG, Hession R, Fox R. Reliability and validity of measures taken during the Chester step test to predict aerobic power and to prescribe aerobic exercise Br J Sports Med. 2004;38(2):197-205. 